\title{
THE EXCHANGE OF GENES BETWEEN NUCLEI OF A DIKARYON
}

\author{
LESLIE K. CROWE \\ Botany Department, Oxford University
}

Received I 2.viii.6o

\section{INTRODUCTION}

THE life cycle of many Basidiomycetes involves a union between compatible monokaryotic strains in which a mutual exchange of nuclei takes place. The process is unusual in that there is a prolonged phase of growth between plasmogamy and karyogamy. The cells of the fruit body and of a variable amount of mycelium do not contain a diploid nucleus but a dikaryon, or pair of haploid nuclei, which divide synchronously, a daughter from each nucleus passing into each new cell. Fusion of the member nuclei of the dikaryon takes place in the basidia, the only cells in which a diploid nucleus has been observed, and is immediately followed by a reduction division and the formation of the haploid basidiospores. It would therefore be expected that genetic recombination would be confined to the nuclear divisions within the basidia. Nevertheless, investigations of mating reactions have yielded results which seem to controvert this conclusion.

The mating system of Schizophyllum commune, Coprinus lagopus and many other Basidiomycetes is controlled by a series of multiple alleles at each of two unlinked loci, A and B. When monokaryotic (sometimes called homokaryotic) mycelia having different alleles at both the loci, (e.g. $\mathrm{A}^{1} \cdot \mathrm{B}^{1}$ and $\mathrm{A}^{2} \cdot \mathrm{B}^{2}$ ), come into contact, an exchange of nuclei takes place after which both mycelia become dikaryotic and are able to produce the typical fruit bodies. The fusion nucleus, being heterozygous at both loci, can give rise to monokaryons of four different mating types, $\mathrm{A}^{1} \cdot \mathrm{B}^{1}, \mathrm{~A}^{1} \cdot \mathrm{B}^{2}, \mathrm{~A}^{2} \cdot \mathrm{B}^{1}$ and $\mathrm{A}^{2} \cdot \mathrm{B}^{2}$. Pairs of mycelia with a common allele exchange nuclei but remain sterile.

The result of mating a monokaryotic mycelium with a dikaryotic mycelium was studied in Coprinus lagopus by Buller (I93I). Three kinds of mating were described: (i) compatible matings in which the monokaryon was compatible with both nuclei of the dikaryon, e.g. $\left(\mathrm{A}^{1} \cdot \mathrm{B}^{1}+\mathrm{A}^{2} \cdot \mathrm{B}^{2}\right) \times \mathrm{A}^{3} \cdot \mathrm{B}^{3}$, (ii) semi-compatible (or hemi-compatible) matings in which the monokaryon was compatible with one nucleus of the dikaryon, e.g. $\left(\mathrm{A}^{1} \cdot \mathrm{B}^{1}+\mathrm{A}^{2} \cdot \mathrm{B}^{2}\right) \times \mathrm{A}^{1} \cdot \mathrm{B}^{1}$ and (iii) incompatible (or non-compatible) matings in which the monokaryon was compatible with neither nucleus of the dikaryon, e.g. $\left(\mathrm{A}^{1} \cdot \mathrm{B}^{1}+\mathrm{A}^{2} \cdot \mathrm{B}^{2}\right) \times \mathrm{A}^{1} \cdot \mathrm{B}^{2}$. The monokaryotic mycelium became dikaryotic in all compatible and semi-compatible matings. The remarkable fact was that dikaryotisation of the monokaryon also occurred in some of the incompatible matings although the reaction was slow and patchy and often failed 
altogether. One explanation suggested was that the dikaryon may be able to produce new mating types which, in these anomalous matings, were compatible with the monokaryons.

Quintanilha (1938) and Papazian (1954) extended Buller's observations. Quintanilha's results leave no doubt that a dikaryon $\mathrm{A}^{1} \cdot \mathrm{B}^{1}$ $+\mathrm{A}^{2} \cdot \mathrm{B}^{2}$ can produce nuclei which are either $\mathrm{A}^{1} \cdot \mathrm{B}^{2}$ or $\mathrm{A}^{2} \cdot \mathrm{B}^{1}$ outside the basidia, but gave no clue to the genetic mechanism involved in the change. Papazian confirmed previous results and by using two marker genes obtained data from three incompatible matings which indicated that recombination of mating type alleles may have occurred between the nuclei of the dikaryon in the hyphal cells. However, the possibility of mutation could not be ruled out.

In an earlier study of compatible matings between monokaryotic and dikaryotic mycelia by Papazian (1950), the further remarkable fact emerged that these matings, like the incompatible combinations, produced new mating types during the vegetative multiplication of the dikaryon despite the compatibility of the parental genotypes. This unexpected result suggested that the nuclei with non-parental mating types may be present in considerable numbers since in a compatible mating they have no obvious selective advantage.

The following experiments with Schizophyllum commune were an attempt to determine how the non-parental genotypes arise during the vegetative multiplication of the dikaryon.

\section{MATERIAL AND METHODS}

The laboratory stock strains of Schizophyllum commune used in these experiments were $\mathrm{A}^{41} c \cdot \mathrm{B}^{41}$ (347), $\mathrm{A}^{41} \cdot \mathrm{B}^{41}(699), \mathrm{A}^{6} \cdot \mathrm{B}^{6} \mathrm{f}$ (108), $\mathrm{A}^{9} \cdot \mathrm{B}^{10} \cdot i$ (130) and $\mathrm{A}^{2} \cdot \mathrm{B}^{2} \cdot u$ (73) (Raper and Miles 1958). From appropriate crosses of these strains other required genotypes were obtained.

TABLE 1

Linkage data and phenotypes of relevant genes in Schizophyllum commune

\begin{tabular}{|c|c|c|c|}
\hline Linkage group & Locus & Map distance & Effect \\
\hline 1 & $\underset{\dot{c}}{\mathrm{~A}}$ & 44 units & $\begin{array}{l}\text { Incompatibility } \\
\text { Concentric ring pattern } \\
\text { on mycelium }\end{array}$ \\
\hline 2 & $\begin{array}{l}\mathrm{B} \\
f\end{array}$ & 32 units & $\begin{array}{l}\text { Incompatibility } \\
\text { Colonies with fir-like } \\
\text { margins }\end{array}$ \\
\hline 3 & $i^{*}$ & - & Indigo pigment present \\
\hline 4 & $u$ & - & Requires uracil \\
\hline
\end{tabular}

* Identical with the "early blue" mutant (Raper and Miles, 1958).

The linkage groups and phenotypes are described in table 1 . None of the mutants is expressed when present in only one nucleus of a dikaryon and none has been known to mutate back to the wild type allele. 
Matings were made on standard medium (Snider and Raper, 1958) in $15 \mathrm{~cm}$. Petri dishes. The monokaryotic mycelium was inoculated first, followed after 48 hours by inoculation with an overlapping disc of dikaryotic mycelium. After an interval of 7 days, new dikaryotic mycelium was present on the fringe of growth emanating from the monokaryotic inoculum.

An agar block bearing hyphæ of the new dikaryotic mycelium was transferred to fruiting medium and after 5 to 10 days, mature fruit bodies were formed.

One fruit body from each new dikaryotic mycelium was suspended over a fresh plate containing standard medium until a sufficient number of spores were shed. The spore deposit was covered with a few drops of sterile water and spread evenly over the plate with a glass rod.

After 24 hours, 20 single germlings from each fruit body were isolated and transferred to small screw-top bottles containing slants of standard medium. Subsequent growth in bottles showed whether the isolates carried the fir $(f)$, concentric (c) or indigo $(i)$ genes. Where the uracilless $(u)$ mutant was involved in a cross, a small block of mycelium was removed from the bottles and placed on minimal (i.e. fruiting) medium. After a second transfer to minimal medium the growth was observed. Uracilless isolates produced no growth while others made rapidly spreading colonies. The suspected uracilless mutants were rescued to minimal medium supplemented with uracil to confirm their specific requirement.

Six monokaryotic testers were used in the mating type analysis. Three were so constituted that each $\mathrm{A}$ allele present in the original mating was combined with a $B$ allele not present in the mated strains. Incompatibility with these testers could only be due to common A alleles. The $\mathrm{B}$ alleles were identified on the same basis.

Dikaryotic mycelia of $S$. commune have widely different capacities to produce fruit bodies. This variation has a genetic basis (Raper and Krongelb, 1958). To avoid problems due to infertility, all strains were crossed to $A^{41} \cdot B^{41}(699)$ for four generations since this is known to be a highly productive strain.

The arrangement of marker genes was basically alike in all matings. The monokaryon was marked with a mutant which was not linked with either the A or the $\mathrm{B}$ loci. In the dikaryon, one of the nuclei carried a mutant linked with the A locus while the other included a mutant linked with the $\mathrm{B}$ locus. The choice and arrangement of markers was restricted since fir $(f)$ was the only available marker for the B locus and concentric $(c)$ the only mutant linked with A which would form a dikaryon in association with a nucleus carrying fir.

In describing matings between monokaryotic and dikaryotic strains, the term dimon will be adopted following Papazian's usage. The inoculated dikaryotic mycelium will be referred to as the parental dikaryotic mycelium to distinguish it from the new dikaryotic mycelium which arises as a result of the migration of nuclei into the monokaryotic mate.

The design of the experiments detects recombination only between nuclei of the parental dikaryon and then only when the recombinant types enter into the new dikaryon.

\section{RESULTS}

(i) Series 1. $A^{9} \cdot B^{10} \cdot \mathrm{i} \times\left(A^{6} \mathrm{C} \cdot B^{41}+A^{41} \cdot B^{6 f}\right)$

Forty-eight replicate matings of the above kind were analysed. There were four reactions.

(a) In the first class thirty-one replicates produced a new dikaryotic mycelium from which the mating types $A^{9} \cdot B^{10}, A^{6} \cdot B^{10}, A^{9} \cdot B^{41}$ and $\mathrm{A}^{6} \cdot \mathrm{B}^{4 \mathrm{t}}$ segregated in the basidiospore progeny. The mutants indigo (i) and concentric $(c)$ also segregated in every family. The alleles $\mathrm{A}^{6}, \mathrm{~B}^{41}$ and $c$ were associated in one nucleus of the parental dikaryon and it is 
therefore concluded that this nucleus migrated and formed the new dikaryon with the resident nucleus, $\mathrm{A}^{9} \cdot \mathrm{B}^{10} . i$ of the monokaryotic mycelium.

(b) In the second class of which there were six representatives, the new dikaryons produced the mating types $\mathrm{A}^{6} \cdot \mathrm{B}^{41}, \mathrm{~A}^{41} \cdot \mathrm{B}^{6}, \mathrm{~A}^{41} \cdot \mathrm{B}^{41}$ and $\mathrm{A}^{6} \cdot \mathrm{B}^{6}$. The mutants concentric $(c)$ and $f i r(f)$ segregated in each of the six families. The A and B alleles and the markers are those which were present in the parental dikaryon. There is therefore reason to believe that the nuclei of the dikaryon can migrate simultaneously, maintaining their association despite the presence of a compatible nucleus in the monokaryotic mycelium through which they pass.

(c) The third class consisted of six families which can be described under three headings.

In four of the replicates the mating types $A^{9} \cdot B^{10}, A^{6} \cdot B^{6}, A^{9} \cdot B^{6}$ and $\mathrm{A}^{6} \cdot \mathrm{B}^{10}$ were present in the progeny. Concentric $(c)$, the marker linked with $\mathrm{A}^{6}$, fir $(f)$, the marker linked with $\mathrm{B}^{6}$ and indigo (i) were also present in each of the four families. $\mathrm{A}^{6}$ and $\mathrm{B}^{6}$ were not present in the same nucleus of the parental dikaryon. Nevertheless they appeared in the progeny from four newly established dikaryotic mycelia associated with their respective markers while $A^{41}$ and $B^{41}$ were absent. Therefore the new genotype $\mathrm{A}^{6} c \cdot \mathrm{B}^{6} f$ is presumed to have arisen by an exchange of genes between the two nuclei of the parental dikaryon and this recombinant nucleus to have subsequently established the new dikaryon with the nucleus from the monokaryotic parent.

A fifth member of the class was identical in all respects to the four described above except for the absence of $f i r(f)$ segregants in the progeny. Thirty additional single spore isolates were examined none of which turned out to be a fir colony. The chance of a sampling error can therefore be dismissed. The origin of this single dikaryotic mycelium is once again attributed to recombination between the nuclei $\mathrm{A}^{6} c \cdot \mathrm{B}^{41}$ and $\mathrm{A}^{41} \cdot \mathrm{B}^{6} f$ to give a new genotype $\mathrm{A}^{6} c \cdot \mathrm{B}^{6}$. Because of the absence of the fir $(f)$ marker, this example was the first indication that the exchanges between the nuclei of the parental dikaryon may not necessarily involve whole chromosomes.

The last member of this class produced progeny with the mating types $A^{41} \cdot B^{41}, A^{41} \cdot B^{10}, A^{9} \cdot B^{41}$ and $A^{9} \cdot B^{10}$. The only mutant to segregate was indigo $(i) . \mathrm{A}^{41}$ and $\mathrm{B}^{41}$ were present in the parental dikaryon but in different nuclei and they were not associated with any markers. In the light of the previous examples and in the absence of $\mathrm{A}^{6}, \mathrm{~B}^{6}$, concentric $(c)$ and fir $(f)$ alleles in this family, it seems reasonable to conclude that a new genotype $A^{41} \cdot B^{41}$ arose by recombination and entered into the new dikaryon.

(d) The fourth class was a heterogeneous collection but its five constituent members shared the common property of sterility. None of the new dikaryotic mycelia produced fruit bodies. On subculturing, three of the sterile mycelia proved to be unstable. Clamp connections were no longer present, the cultures were indigo in colour and in each 
case the mating type was $\mathrm{A}^{9} \cdot \mathrm{B}^{10}$ thus indicating that these three strains had reverted to a monokaryotic state.

The two remaining sterile dikaryotic mycelia were stable. Because of their sterility, a new approach was necessary to find out their genotype. They were first mated with a completely unrelated monokaryotic strain $\mathrm{A}^{1} \cdot \mathrm{B}^{2}$. The new dikaryons produced as a result of these dimon matings were allowed to fruit and in both cases indigo colonies and the alleles $\mathrm{A}^{9}$ and $\mathrm{B}^{\mathbf{1 0}}$ were recovered in the progeny, indicating that $\mathrm{A}^{9} \cdot \mathrm{B}^{10} . i$ was one of the nuclei present in the sterile dikaryotic parents. The other nucleus could have carried $\mathrm{A}^{41} \cdot \mathrm{B}^{6}, \mathrm{~A}^{6} \cdot \mathrm{B}^{41}$ or a new combination of these alleles. To distinguish between the alternatives, the two sterile dikaryons were mated with $\mathrm{A}^{41} \cdot \mathrm{B}^{10}, \mathrm{~A}^{6} \cdot \mathrm{B}^{10}, \mathrm{~A}^{9} \cdot \mathrm{B}^{6}$ and $A^{9} \cdot B^{41}$ as testers. The results of these matings showed that in one of the dikaryotic mycelia the second nucleus carried the alleles $\mathrm{A}^{6}$ and $\mathrm{B}^{41}$, the full genotype therefore being $\mathrm{A}^{9} \cdot \mathrm{B}^{10}+\mathrm{A}^{6} \cdot \mathrm{B}^{41}$. In the other dikaryon the second nucleus had the recombinant genotype $\mathrm{A}^{6}$. $\mathrm{B}^{6}$. The test matings produced dikaryons which were again sterile and consequently attempts to determine which markers were present were abandoned.

\section{(ii) Series 2. $A^{9} \cdot B^{10} \cdot \mathrm{i} \times\left(A^{6} B^{41} \mathrm{f}+A^{41} \mathrm{c} \cdot B^{6}\right)$}

Ten replicates of the above cross were analysed. The results showed that seven of the newly-formed dikaryons combined the nucleus of the monokaryotic parent with one of the nuclei of the parental dikaryon. These dikaryons had the genotype $\mathrm{A}^{9} \cdot \mathrm{B}^{10} \cdot i+\mathrm{A}^{6} \cdot \mathrm{B}^{41} f$ and their origin was the same as the first category in the previous series.

In one case the new dikaryon was genetically identical with the parental dikaryon thus corresponding with the second class in the first series of replicates. The last two replicates produced new dikaryotic mycelia which proved to have the genotype $\mathrm{A}^{9} \cdot \mathrm{B}^{10} \cdot i+\mathrm{A}^{6} \cdot \mathrm{B}^{6}$. These are assumed to have arisen after the production of the recombinant genotype $\mathrm{A}^{6} \cdot \mathrm{B}^{6}$ in the parental dikaryon and therefore correspond with the third class in the first series.

\section{(iii) Series 3. $A^{2} \cdot B^{2} \cdot \mathrm{u} \times\left(A^{41} \mathrm{C} \cdot B^{41}+A^{6} \cdot B^{6 f}\right)$}

There were twenty-one replicates of this dimon mating. Again classes $(a),(b)$ and $(c)$ of the first series were represented. In sixteen new dikaryons the nucleus of the monokaryotic parent was associated with one of the nuclei from the parental dikaryon. Of these, ten had the genotype $\mathrm{A}^{2} \cdot \mathrm{B}^{2} \cdot u+\mathrm{A}^{41} c \cdot \mathrm{B}^{41}$ and six were $\mathrm{A}^{2} \cdot \mathrm{B}^{2} \cdot u+\mathrm{A}^{6} \cdot \mathrm{B}^{6} f$. In one of the new dikaryons the genotype was the same as that of the parental dikaryon. There were three examples of recombination; $\mathrm{A}^{2} \cdot \mathrm{B}^{2} \cdot u+\mathrm{A}^{41} \cdot \mathrm{B}^{6} f, \mathrm{~A}^{2} \cdot \mathrm{B}^{2} \cdot u+\mathrm{A}^{41} c \cdot \mathrm{B}^{6}$ and $\mathrm{A}^{2} \cdot \mathrm{B}^{2} \cdot(\mathrm{S})+\mathrm{A}^{6} \cdot \mathrm{B}^{41}$.

The last member of this series was unique. The new dikaryon had the genotype $\mathrm{A}^{2} \cdot \mathrm{B}^{2}+\mathrm{A}^{6} \cdot \mathrm{B}^{6}$ and therefore had two non-parental genotypes. One of these is probably a recombinant derived from the parental dikaryon but the origin of the other, which had the mating 
type of the parental monokaryon although the marker was absent, is doubtful. It may be that there was a back mutation of the uracilless gene to the wild type allele or alternatively there may have been

TABLE 2

A summary of the results of seventy-six dimon matings in Schizophyllum commune

\begin{tabular}{|c|c|c|c|c|}
\hline \multirow{3}{*}{ Dikaryon } & \multicolumn{4}{|c|}{ Migrating nuclei } \\
\hline & \multicolumn{2}{|c|}{ Parental } & \multicolumn{2}{|c|}{ Recombinant } \\
\hline & One & Both & $\begin{array}{l}\text { Independent } \\
\text { assortment }\end{array}$ & $\begin{array}{c}\text { Crossing- } \\
\text { over }\end{array}$ \\
\hline $\begin{array}{l}\mathrm{A}^{6} c \cdot \mathrm{B}^{41}+\mathrm{A}^{41} \cdot \mathrm{B}^{6} f \\
\mathrm{~A}^{6} \cdot \mathrm{B}^{41} f \cdot+\mathrm{A}^{41} c \cdot \mathrm{B}^{6} \\
\mathrm{~A}^{41} c \cdot \mathrm{B}^{41}+\mathrm{A}^{6} \cdot \mathrm{B}^{6} f\end{array}$ & $\begin{array}{r}32 \\
7 \\
\times 6\end{array}$ & $\begin{array}{l}6 \\
I \\
I\end{array}$ & $\begin{array}{l}6 \\
2 \\
1\end{array}$ & $\frac{I}{3}$ \\
\hline $\begin{array}{l}\text { Total } \\
\text { Percentage }\end{array}$ & $\begin{array}{l}55 \\
72 \cdot 3\end{array}$ & $\begin{array}{c}8 \\
10 \cdot 5\end{array}$ & $\underset{\text { I }}{9} \cdot 8$ & $\begin{array}{l}4 \\
5 \cdot 1\end{array}$ \\
\hline
\end{tabular}

recombination between the $\mathrm{A}^{2} \cdot \mathrm{B}^{2} \cdot u$ nucleus and another of the parental nuclei which was not included in the new dikaryon.

The results of the three series of matings are summarised in table 2.

\section{DISCUSSION}

Following Buller's demonstration of the unexpected dikaryotisation of the monokaryotic parent in incompatible dimon matings, three different interpretations were proposed.

\section{(i) Migration of the dikaryotic nuclei}

Buller himself suggested that the nuclei of the dikaryon migrated and supplanted the resident nucleus in the monokaryotic mycelium. This interpretation was also supported by Dickson (I935), Chow (I934) and Oikawa (1939). From the data presented in the present paper, it would seem that migration of the dikaryotic nuclei does occur in a minority of matings. Although there is no proof that in these cases an occasional hypha of the parental dikaryon does not penetrate the interstices of the monokaryotic mycelium, Terekawa's (I957) observations of nuclei migrating from a dikaryon in pairs lend support to the interpretation of synchronous migration of the dikaryon's nuclei.

\section{(ii) Mutation}

The second proposal involved the mutation of one of the incompatibility genes to an allele which rendered one of the nuclei of the dikaryon compatible with the monokaryon. As evidence from dimon 
matings accumulated, this explanation became increasingly improbable since the mating type of the new nucleus always included the $\mathrm{A}$ allele of one nucleus of the dikaryon and the B allele of the other. The use of markers has now shown that in certain cases two mutations would be required and this is doubly unlikely. There is indeed no evidence which supports this explanation in preference to others.

\section{(iii) Recombination}

Quintanilha and Papazian considered that new nuclei arose from elements of the existing dikaryon. Without mutants which are linked with the $\mathrm{A}$ and $\mathrm{B}$ loci it is impossible to discriminate between mutation and recombination of these loci and neither author had the necessary mutants available. In $S$. commune however, markers became available and their use in the present experiments vindicates Quintanilha's and Papazian's conclusions.

The validity of the recombination theory in relation to dimon matings rests of course, on the premise that the fruit body of $S$. commune is never composed of sectors in which the cells contain genetically different nuclei. The experimental evidence in favour of the genetic homogeneity of the fruit body is, however, sound. In the course of investigations by a number of different workers, the progeny from a very large number of fruit bodies of $S$. commune have been analysed and a chimæra has never been reported. So there can be little doubt that the non-parental genotypes recovered in these experiments are the products of genuine recombination occurring during the multiplication of the nuclei in the parental dikaryotic mycelium.

Some of the recombinant genotypes appear to have been the result of independent assortment of whole chromosomes while others can only have arisen by crossing-over between homologous chromosomes. Although the mechanics by which these events occur are far from clear, crossing-over requires pairing of chromosomes and this can take place only in a fusion nucleus. The behaviour of $S$. commune therefore reveals an apparent contradiction. Cytological observations indicate that the only diploid nuclei are in the basidia. Genetical results indicate that diploidy must also occur in other cells. However there are so far no data on which to predict accurately the frequency of these diploid nuclei and it may be that their incidence is rare enough to account for the discrepancy.

The fusion of the nuclei of the dikaryon in hyphal cells poses the question of how the nuclei are again reduced to the haploid state. A prolonged diploid phase is unlikely in view of the cytological data. Since diploidy is the immediate prelude to reduction in the basidia it may also be so in the hyphal cells. Again it is not known whether the recombination is the result of meiosis or a parasexual mechanism such as that demonstrated in a number of Ascomycetes (Pontecorvo and Kafer, 1958). This latter interesting possibility must be taken into account in future investigations. 
In conclusion, the significant deviation from an expected I : I ratio in the occurrence of $\mathrm{A}^{9} \cdot \mathrm{B}^{10} \cdot i+\mathrm{A}^{41} \cdot \mathrm{B}^{6} f$ and $\mathrm{A}^{9} \cdot \mathrm{B}^{10} \cdot i+\mathrm{A}^{6} c \cdot \mathrm{B}^{41}$ dikaryons in the first series of replicate matings and a comparable deviation in the second series is not at present understood. Such deviations are by no means uncommon. Kimura (1954) studied this effect in Coprinus microrhizus to discover what factors decide the choice of dikaryotising nuclei in compatible dimon matings. He concluded that a cytoplasmic factor was involved. Preliminary tests with $S$. commune suggest that the choice of dikaryotising nuclei is directly influenced by the mating types involved and more particularly by the structure of the $\mathrm{A}$ and $\mathrm{B}$ alleles as described by Raper, Baxter and Middleton (1958). The problem of differential affinity between mating types is the subject of further experiments.

\section{SUMMARY}

The dikaryotisation of monokaryons in compatible dimon matings of $S$. commune occurs in two ways.

I. By the association of the nucleus of the monokaryon with one of the parental nuclei of the dikaryon.

2. By the association of the nucleus of the monokaryon with a nucleus of non-parental genotype from the dikaryon.

In addition, both nuclei of the dikaryon may migrate intact through the monokaryotic mycelium.

Using genetic markers, it has been shown that non-parental mating types arise by recombination between the two component nuclei of the dikaryon in the absence of fruit bodies and basidiospores. In some cases the exchange of genetic material seems to result from independent assortment of chromosomes and in others, from crossing-over between homologous chromosomes.

It is uncertain whether recombination is caused by the parasexual processes of haploidisation and mitotic recombination such as have been described in Ascomycetes or by precocious fusion of the nuclei of the dikaryon followed by meiosis.

Acknowledgments.-This work was undertaken during the tenure of the Helen Putnam Memorial Fellowship at Radcliffe College, Cambridge, Mass., U.S.A. Laboratory expenses were defrayed by the U.S. Public Health Authority (Grant No. 3334). The author wishes to express her appreciation of the facilities provided at the Department of Biology, Harvard University and especially to Professor J. R. Raper who provided the stocks of Schizophyllum and made many useful suggestions during the course of the investigation. Thanks are also due to Mrs M. Benson for her technical assistance.

\section{REFERENCES}

BUller, A. H. R. I93I. Researches on Fungi IV. Longmans, Green and Co., London• chow, c. H. 1934. Contribution à l'étude du development des coprins. Le Botanist, $26,89-232$.

Dickson, H. 1935. Studies in Coprinus spharosporus II. Ann. Bot., 49, I8I-204. 
KIMURA, K. 1954. On the diploidization of the doubly compatible diploid mycelium in the Hymenomycetes. Bot. Mag. (Tokyo), 67, 238-242.

orKaWA, к. 1939. Diploidisation and fruit body formation in the Hymenomycetes. Sci. Rep. Tohoku Imp. Univ., I4, 245-26o.

PAPAZIAN, H. P. 1950. Physiology of the incompatibility factors in Schizophyllum commune. Bot. Gaz., II2, I43-163.

PAPAZIAN, H. P. 1954. Exchanges of incompatibility factors between the nuclei of a dikaryon. Science, IIg, 69I-693.

PONTECORVO, G., AND KAFER, E. 1958. Genetic analysis based on mitotic recombination. Ad. Gen., 9, 7 I-104.

Quintanilha, A. 1938. Etude genetique du phénomène du Buller. Bol. Soc. Brot., Ser. 2, $13,425-486$.

RAPER, J. R., BAXTER, M., AND MIDDLETON, R. I958. The genetic structure of the incompatibility factors in Schizophyllum commune. Proc. Nat. Acad. Sci., 44, 889-900.

RAPER, J. R., AND MILES, P. G. 1958. The genetics of Schizophyllum commune. Genetics, $43,530-546$.

RAPER, J. R., AND KRONGELB, G. S. 1958. Genetic and environmental aspects of fruiting in Schizophyllum commune. Mycologia, 50, 707-740.

SNIDER, P. J., AND RAPER, J. R. I958. Nuclear migration in the Basidiomycete, Schizophyllum commune. Am. 7. Bot., 45, 538-546.

TERAKAwA, H. 1957. The nuclear behaviour and morphogenesis of Pleurotus ostreatus. Sci. Papers Col. Gen. Educ. Univ. Tokyo, 7, 61-88. 